$\pm N / E$

Global burnals Inc.

है 5 है

\title{
Results of a Questionnaire on Teeth for 118 People Who Participated in the University Festival
}

\author{
By Naomi Katayama \& Shyoko Kondo
}

Nagoya Women's University

Abstract- A dental questionnaire survey conducted on 34 high school students, 55 university students, 23 Middle-age who participated in the university festival. Participants answered yes or no to ten self-administered questions. Also, participants described the hardness of meals, brushing teeth after meals, and time to spend eating in a questionnaire. As a result, some students even had some guminflammation. Middle -Ages had many people who had experience with swollen gums (52.2\%). Of the participants, the Middle Ages were few who applied fluorine (17.4\%), and many were students (high school students 64.7\%, university students $90.9 \%$ ). Most people brush their teeth after breakfast or dinner. Participants replied that they usually eat a little hard (52.0\%) or soft (38.1\%) food. One high school student replied that he usually eats soft food. The time to eat was longer than breakfast and then dinner, but it was less than 30 minutes ever for dinner. Middle-Ages ad an average time to spend eating of fewer than 10 minutes for breakfast, 14 minutes for lunch, and 22 minutes for dinner. Middle ages had shorter meal times in all than students. Form the results of the participants; we wondered if they did not chew food very well because they eat soft food in a short time.

Keywords: tooth, questionnaire survey, university festival.

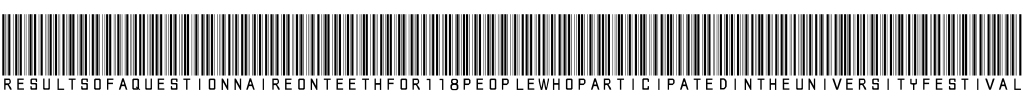

Strictly as per the compliance and regulations of:

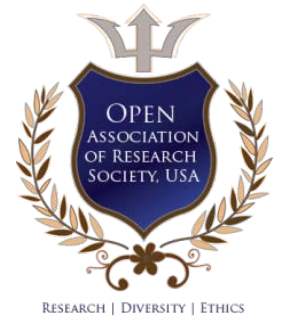

(c) 2020. Naomi Katayama \& Shyoko Kondo. This is a research/review paper, distributed under the terms of the Creative Commons Attribution-Noncommercial 3.0 Unported License http://creativecommons.org/licenses/by-nc/3.0/), permitting all noncommercial use, distribution, and reproduction in any medium, provided the original work is properly cited. 


\title{
Results of a Questionnaire on Teeth for 118 People Who Participated in the University Festival
}

\author{
Naomi Katayama ${ }^{\alpha}$ \& Shyoko Kondo ${ }^{\sigma}$
}

Abstract- A dental questionnaire survey conducted on 34 high school students, 55 university students, 23 Middle-age who participated in the university festival. Participants answered yes or no to ten self-administered questions. Also, participants described the hardness of meals, brushing teeth after meals, and time to spend eating in a questionnaire. As a result, some students even had some guminflammation. Middle-Ages had many people who had experience with swollen gums (52.2\%). Of the participants, the Middle Ages were few who applied fluorine $(17.4 \%)$, and many were students (high school students $64.7 \%$, university students $90.9 \%$ ). Most people brush their teeth after breakfast or dinner. Participants replied that they usually eat a little hard $(52.0 \%)$ or soft $(38.1 \%)$ food. One high school student replied that he usually eats soft food. The time to eat was longer than breakfast and then dinner, but it was less than 30 minutes ever for dinner. Middle-Ages ad an average time to spend eating of fewer than 10 minutes for breakfast, 14 minutes for lunch, and 22 minutes for dinner. Middle ages had shorter meal times in all than students. Form the results of the participants; we wondered if they did not chew food very well because they eat soft food in a short time. Keywords: tooth, questionnaire survey, university festival.

\section{INTRODUCTION}

U nlike primitive people, modern people have smaller jaws and weaker biting power. Maintaining a healthy oral condition helps maintain and improve health. In Japan, there is an 8020 campaign (keeping 20 teeth until age 80). Tooth brushing learned during kindergarten and elementary school, and it needs to teach at home. However, it is often impossible to brush each after meals. It has reported overseas that tooth education has a good effect on tooth brusing ${ }^{1,2}$. Similarly, for other dental care, there is a good point that knowledge and education about teeth motivate ${ }^{3,4)}$. It is good to provide oral care because keeping healthy teeth affects our eating habits. Therefore, this study reports the results of a questionnaire survey on teeth for participants who visited the university festival.

Author a: Graduate School of Nagoya Women's University, Nagoya City, Japan.

Corresponding Author a: Nagoya Women's University, Nagoya City, Japan.e-mail:naomik@nagoya-wu.ac.jp

Author $\sigma:$ Watanabe Hospital, Noma, Aichi, Japan.

\section{il. Materials and Methods}

a) Participants

Participants were 34 high school students, 55 university students, and 23 middle-age people. Participants voluntarily participated in the survey.

b) Questionnaire survey method

The questionnaire items for teeth shown in Table 2. First of all, the participants answered ten items shown in Table 2 in a self-administered from with a yes or no answer. After that, participants described in the questionnaire about the hardness of meals they usually eat and the average time (minutes) to eat.

Finally, at the time of participation, multiple answers were given when brushing teeth (after breakfast, after lunch, after dinner, after snack).

Table 2: Questionnaire result about tooth (Yes or No)

\begin{tabular}{l} 
Partial dentures \\
full dentures \\
dentures \\
currently going to the dentist \\
udergoing regular dental check-ups \\
some currently undergoing treatment \\
habing toothpaste \\
swollen gums \\
interested in toooth \\
fluorine application in elementary school \\
\hline \hline
\end{tabular}

c) Ethical review board

This study conducted with the approval of the Ethical Review Board (Nagoya women's university 'hitowo mochiita kennkyuunikansuru iinnkai'). The approval number is $30-7$ and $30-17$.

\section{Results}

\section{a) Participants}

Participants were 34 high school students, 55 university students, and 23 middle-age people. Participants voluntarily participated in the survey. Table 1 shows the average and standard deviation (SD) of the age of participants, the average and SD of height, and the average and SD of weight. 
Table 1: Average and standard deviation (SD) of participants' age, height and weight

\begin{tabular}{lccc}
\hline & Age & Height & Weight \\
\cline { 2 - 4 } & Average \pm SD & Average \pm SD & Average \pm SD \\
\hline High school students $(n=34)$ & $17.03 \pm 0.67$ & $157.17 \pm 5.12$ & $48.27 \pm 6.60$ \\
Female college student $(n=55)$ & $20.46 \pm 0.54$ & $157.76 \pm 6.20$ & $50.35 \pm 4.48$ \\
Middle age $(n=23)$ & $47.14 \pm 2.61$ & $159.71 \pm 8.43$ & $54.94 \pm 10.10$ \\
\hline \hline
\end{tabular}

b) Questionnaire results

Among the participants, 34 high school students answered ten questions about teeth, as shown in Table 3. High school students answered that they had no partial or full dentures. However, there were high school students who answered that the gums had swollen (35.3\%).

Table 3: Questionnaire result about tooth for high school students $(n=34)$

\begin{tabular}{lccc}
\hline \hline & Yes & No & No answer \\
\hline Partial dentures & 0 & 34 & \\
full dentures & 0 & 34 & \\
dentures & 1 & 33 & \\
currently going to the dentist & 13 & 21 & \\
udergoing regular dental check-ups & 3 & 31 & \\
some currently undergoing treatment & 3 & 31 & \\
habing toothpaste & 13 & 21 & \\
swollen gums & 12 & 22 & \\
interested in toooth & 13 & 21 & \\
fluorine application in elementary scho & 22 & 10 & 2 \\
\hline \hline
\end{tabular}

Table 4 shows the results of questions about or full dentures, but someone had swollen gums dental that university students made. Similar to high (25.5\%). Also, more university students applied fluoride school students, university students do not have partial to their teeth (90.9\%) than high school students (64.7\%).

Table 4: Questionnaire result about tooth for female university students $(n=55)$

\begin{tabular}{lccc}
\hline \hline & Yes & No & No answer \\
\hline Partial dentures & 0 & 55 & \\
full dentures & 0 & 55 & \\
dentures & 1 & 54 & \\
currently going to the dentist & 6 & 49 & \\
udergoing regular dental check-ups & 19 & 36 & \\
some currently undergoing treatment & 3 & 52 & \\
habing toothpaste & 11 & 44 & \\
swollen gums & 14 & 41 & \\
interested in toooth & 23 & 32 & \\
fluorine application in elementary school & 50 & 4 & 1 \\
\hline \hline
\end{tabular}

Table 5 shows the results of the questionnaire regarding middle-age teeth. The middle-age also had no a trial or full dentures. Middle Age often had swollen gums (52.2\%), and few of them applied fluoride (17.4\%). 
Table 5: Questionnaire result about tooth for middle age $(\mathrm{n}=23)$

\begin{tabular}{lccc}
\hline \hline & Yes & No & No answer \\
\hline Partial dentures & 0 & 23 & \\
full dentures & 0 & 23 & \\
dentures & 10 & 13 & \\
currently going to the dentist & 3 & 20 & \\
udergoing regular dental check-ups & 8 & 15 & \\
some currently undergoing treatment & 3 & 20 \\
habing toothpaste & 17 & 6 \\
swollen gums & 12 & 11 \\
interested in toooth & 10 & 13 \\
fluorine application in elementary scho & 4 & 19 & \\
\hline \hline
\end{tabular}

We asked the participants about the hardness usually eat were a little hard or a little soft. However, a of the food they usually eat (see Table 6 and 7). As a high school student answered the question that she eat result, most participants answered that the foods they soft food.

Table 6: Hardness of the usually-eat-meal $(n=112)$

\begin{tabular}{lccccc}
\hline \hline & Hard & Slightly hard & Slightly soft & Soft & No answer \\
\hline High school students $(\mathrm{n}=34)$ & 1 & 17 & 13 & 1 & 2 \\
Female college student $(\mathrm{n}=55)$ & 3 & 33 & 18 & 0 & 1 \\
Middle age $(\mathrm{n}=23)$ & 2 & 10 & 10 & 0 & 1 \\
\hline \hline
\end{tabular}

Table 7: Hardness of the usually-eat-meal $(\%)(n=112)$

\begin{tabular}{lccccc}
\hline \hline & Hard & Slightly hard & Slightly soft & Soft & No answer \\
\hline High school students $(\mathrm{n}=34)$ & 2.9 & 50 & 38.2 & 2.9 & 5.9 \\
Female college student $(\mathrm{n}=55)$ & 5.5 & 60.0 & 32.7 & 0.0 & 1.8 \\
Middle age $(\mathrm{n}=23)$ & 8.7 & 43.5 & 43.5 & 0 & 4.3 \\
\hline
\end{tabular}

We asked the participants about the time to eat lunch than breakfast and more dinner than lunch. But (see Table 8). As a result, they were spending more the middle-ages took less time in all than the students.

Table 8: Comparison of average time \pm standard diviation for one meal (minute)

\begin{tabular}{lccc}
\hline & Breakfast & Runch & Dinner \\
\hline High school students $(\mathrm{n}=34)$ & $14.1 \pm 6.3$ & $22.9 \pm 8.4$ & $29.1 \pm 12.6$ \\
Female college student $(\mathrm{n}=55)$ & $14.6 \pm 9.4$ & $21.9 \pm 9.2$ & $28.4 \pm 14.8$ \\
Middle age $(\mathrm{n}=23)$ & $9.8 \pm 3.3$ & $13.6 \pm 5.6$ & $21.6 \pm 12.7$ \\
\hline \hline
\end{tabular}

The participants asked whether they would brush their teeth after eating with multiple answers (see Table 9). As a result, most participants answered that they would brush their teeth after breakfast and dinner. They would not polish after lunch.

Table 9: Brush the teeth every time or not (numbers)

\begin{tabular}{lcccc}
\hline & Morning & Daytime & Night & Do not \\
\hline High school students $(\mathrm{n}=34)$ & 24 & 1 & 24 & 0 \\
Female college student $(\mathrm{n}=55)$ & 44 & 1 & 44 & 0 \\
Middle age $(\mathrm{n}=23)$ & 12 & 3 & 11 & 0 \\
\hline \hline
\end{tabular}




\section{Discussion}

As a result of questions about teeth to people who attended this university festival, no one had full or partial dentures until the middle-ages. Most participants answered that they would brush their teeth after breakfast and dinner. They would not polish after lunch. It reported that many students abroad brush their teeth twice or more a day ${ }^{5)}$. In particular, females brushed their teeth better than males and used dental floss ${ }^{5,6)}$. The participants in the middle-ages were applying fluorine than students, and many had swollen gums. Also, the time to spend eating for breakfast and lunch were short and tended to eat soft foods. Middle-ages are the age that requires the prevention of alveolar pyorrhea, and maintaining 20 teeth by the age of 80 is likely to be difficult if the teeth are not valued. It has reported that the results of middle-age teeth surveys overseas also indicate that gingivitis and inflammation around the teeth are common ${ }^{7}$. And education should be provided from the perspective of public health ${ }^{7)}$. Many participants, ever student, have experience with swollen gums. Itreported that a few Japanese people control plaque ${ }^{8)}$. It also reported that there are many Koreans who are the same Asian people who bleed from their gums when brushing their teeth compared to Americans ${ }^{9)}$. Since the staple food of Asians is rice, it may be one of the causes of gingivitis that it is tender and sticky and easily attaches to teeth. Also, in this study, since a high school student answered that she usually eats soft foods, we thought it would be good to investigate how much chewing power they had. The Japanese staple food is rice, which is soft, so we would like to find out if it has enough chewing power.

\section{Conclusions}

A questionnaire survey on teeth was conducted for thig school students, university students, Middle Ages who participated in the university festival. As a result, many young students had swollen gums, and few the middle-ages were applying fluoride. Participants replied that they would eat either hard or soft food in their usual diet. Participants spent less time (20-30 minutes) on meals of all ages, with Middle Age having breakfast within 10 minutes, lunch within 15 minutes, and dinner around 20 minutes. There are many soft foods in the Japanese diet, and we would like to find out by grasping whether or not they have sufficient chewing power.

\section{Acknowledgements}

This study was supported by the Japanese Society of Taste Technology, 2019.

\section{References Références Referencias}

1. Nusair KB, Alomari Q, Said K. Dental health attitudes and behaviour among dental students in Jordan. Community Dent Health. 2006; 23:147-151.

2. Al-Wahadni AM, Al-Omiri MK, Kawamura M. Differences in self-reported oral health behavior between dental students and dental technology/dental hygiene students in Jordan. J Oral Sci. 2004; 46:191-197.

3. Cortes FJ, Nevot C, Ramon JM, Cuenca E. The evolution of dental health in dental students at the University of Barcelona. J Dent Educ. 2002; 66:1203-1208.

4. Polychronopoulou A, Kawamura M, Athanasouli T. Oral self-care behavior among dental school students in Greece. J Oral Sci. 2002; 44:73-78.

5. Kirtiloglu T, Yavuz US. An assessment of oral selfcare in the student population of a Turkish university. Public Health. 2006; 120:953-957.

6. Al-Omari QD, Hamasha AA. Gender-specific oral health attitudes and behavior among dental students in Jordan. J Contemp Dent Pract. 2005; 6:107-114.

7. Brodeur JM, Payette M, Beniger M, Charbonneau A, Olivier M, Chabot D. Periodontal diseases among Quebec adults aged 35 to 44 years. J Can Dent Assoc. 2001; 67:34.

8. Kawamura M, Iwamoto $\mathrm{Y}$, Wright FA. A comparison of self-reported dental health attitudes and behavior between selected Japanese and Australian students. J Dent Educ. 1997; 61:354-360.

9. Kawamura M, Spadafora A, Kim KJ, Komabayashi T. Comparison of United States and Korean dental hygiene students using Hiroshima University-Dental Behavioural Inventory (HU-DBI) Int Dent J. 2002; 52:156-162. 